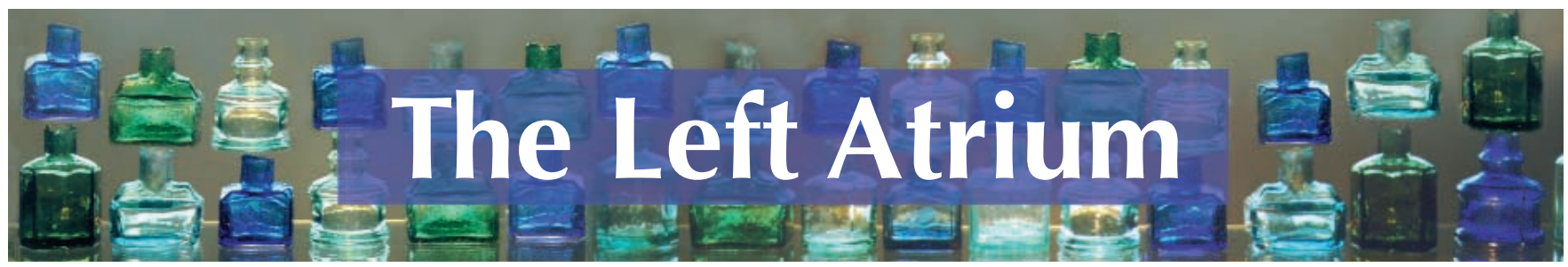

\section{A casebook study}

Island doctor: John Mackieson and medicine in nineteenth-century Prince Edward Island David A.E. Shephard

Montréal and Kingston: McGill-Queen's University Press; 2003 187 pp \$44.95 (cloth) ISBN 0-7735-2524-6

A the ready age of 20 years, one John Mackieson, born in 1795 in Stirlingshire, was declared after studies at Glasgow University in anatomy, surgery, chemisty, midwifery and materia medica "a fit and capable person to exercise the Arts of Surgery and Pharmacy." He had earned a "country licentiate" rather than the degree of Doctor of Medicine, but this was good enough for the burgeoning population of Charlottetown, PEI, where Mackieson settled in 1821 and practised for 64 years.

As David Shephard reflects in his introduction, his account of Mackieson's career falls into the "growing literature of microhistory that deals with the lives and careers of 'ordinary' doctors" and teaches us the reality rather than the ideal of medical practice in a former time. Mackieson was well trained, adept (he was the first physician in PEI to repair a strangulated inguinal hernia) and respected. His marriage to the daughter of a prominent merchant and politician paved the way to a series of public roles, including health officer of the city port, medical attendant to its jail, medical superintendent of the Charlottetown Lunatic Asylum (the first such institution in Canada), surgeon-general to the militia, founding chairman of the PEI Medical Association and Elder of the Kirk. There would have been ample documentary traces of Mackieson's life to assure him some small share of posterity, even if he had not left his own archive of professional practice: his "Sketches of Medical and Surgical Cases," in which he entered 257 medical cases, a second casebook detailing the histories of 115 patients with mental illness, a "Codex of Medical Experi- ence," which summarized readings from the medical literature, and a copious therapeutic "Formulary."

Shephard, archivist of the Canadian Anesthesiologists' Society, has constructed a coherent narrative from Mackieson's manuscripts and other sources. Island Doctor is a readable account of the social life of Mackieson's Charlottetown, the state of medicine and medical professionalism in his day, and the clinical challenges he faced. His career made a somewhat awkward bridge between 18th- and 19th-century medicine. His education had its roots in the Scottish Enlightenment, with all that implied for a rational and empirical approach, but predating microbiology and an understanding of hygiene, it retained some of the logic of humoral theory and dealt in symptoms more than disease entities. As Shephard writes, "Mackieson's techniques were limited to the use of his physical senses, and ... his diagnostic data were obtained from observation of the skin, the pulse, the patient's blood and excreta, and of signs and symptoms that pinpointed the disease."

Far removed in the colonies from scientific advances elsewhere, he does not refer to the use of the stethoscope, which Laennec introduced in 1816, until 1842. He practised bloodletting long after its benefits had been disputed, and considered anesthesia too risky. But, while Mackieson's practice was hardly on the cutting edge, it was not untypical. As Shephard notes, the "unholy trinity' of emetics, purgatives, and bloodletting [that Mackieson used] was a mainstay of treatment in the nineteenth century." Thus we must contain our horror when he lets blood from a woman with placenta previa, and, since he would not have known about Semmelweis or Holmes, forgive his insouciance of the cause of puerperal fever. (After all, he was skilled at manually turning a fetus and in using forceps in moments of obstetric peril.) Given Shephard's selection of cases, many of Mackieson's interventions appear to have ended in disaster accelerated by the use of "heroic" measures that depleted the patient of fluids and recuperative resources. But the picture that emerges is often pitiable for patient and physician alike, as in his futile attempt to save a child with severe burns. In each case we find Mackieson trying every means he knew to assist his patient - and these often amounted to an astounding array of remedies and comforts. For a man with compound fracture of the leg, Mackieson prescribed "quinine sulfate, wine and water, small doses of castor oil, and Seidlitz powder, together with a diet of eggs and tea for breakfast and beef steak for dinner."

There were two great blemishes on Mackieson's career. The first involved a failure to detect typhus in a ship arriving with Irish immigrants and a subsequent failure to impose effective quarantine. The second and worse story ended in his indictment at the age of 79 for having "neglected and disregarded his duty" toward the inmates of the asylum, who were discovered in a deplorable state. This is a sad and incomprehensible late chapter in the career of a physician who had, in his prime, attempted to implement humane reforms in the treatment of mental illness.

Shephard's exploration of the Mackieson archive is thus no hagiography or nostalgic reconstruction of medicine in a quainter age. It makes for fascinating reading, and one suspects that medical historians have not yet finished with the enigmatic story of Dr. John Mackieson.

\section{Anne Marie Todkill}

CMAF 